\title{
The application of real option valuation techniques in the cellular telecommunication industry in South Africa
}

\author{
M. Mkhize* \\ Wits Business School, University of Witwatersrand \\ mkhizeh2@yahoo.com \\ N. Moja \\ University of Witwatersrand \\ Received May 2009
}

\begin{abstract}
The purpose of this paper is to examine whether real option valuation techniques can be used by cellular telecommunication operators in South Africa when making capital investment decisions in next-generation serviceorientated architectures. Prior studies, in other parts of the world, recommend the use of real option valuation techniques by telecommunication operators when conducting capital budgeting. In this study, both Black-Scholes and Binomial models are used to examine their effectiveness in valuing capital investments within a cellular telecommunication industry in South Africa. Results show that real option valuation techniques are effective in analysing investments in cellular telecommunication industry. Their strengths are mostly demonstrated when determining the value of strategic options that are added to traditional (base-case) net present value. Summary and conclusions are provided.
\end{abstract}

*To whom all correspondence should be addressed.

\section{Introduction}

\section{Background}

Dai, Kauffman and March (2000) explain that senior executives are required to justify information technology (IT) investment projects in financial terms. However, the challenge they are facing is that they struggle to establish the correct value-added estimate for the newest and most innovative technologies. According to Dai et al. (2000: 1), a survey conducted by Information Week in 1998 indicated that approximately $80 \%$ of 150 information system (IS) executives at United States (US) companies had been required to justify IT projects in financial terms. These results are expected especially because a single IT investment usually requires a large amount of money in the form of capital expenditure, operating costs and, equally important, maintenance and replacement costs. For example, the JSE Securities Exchange South Africa (JSE) spent millions of rand on the London-based Securities Exchange Trading System (SETS), when converting from the Johannesburg Equities Trading (JET) to SETS. Therefore, it is imperative to justify these IT investments in financial terms.

Cellular telecommunications operators face the complex challenge of having to make the right investment choices amidst rapidly evolving technology, and to deploy the technology at the right time (Iatropoulos, Economides, \& Angelou, 2004). According to Iatropoulos et al. (2004) and Pollet, Maas, Marien and Wambecq (2006), it is important to address this challenge, given the high capital requirements for telecommunications infrastructure investments, volatile cash flows due to variability of customers' demand for a service, and the technology risk that may result in failed deployments. An example provided by Harmantzis and Tanguturi $(2007: 107)$ is the case where an operator needs to make a decision on whether to invest in expanding a network from $2.5 \mathrm{G}$ to $3 \mathrm{G}$, defer the investment, or invest in alternate technologies such as WiMax. This is, of course, a challenging decision to make.

Senior management at a South African cellular telecommunications operator argue that the decision to invest in the next-generation service architecture is essentially a capital budgeting decision, one that maximizes financial value and incorporates strategic planning and technology fit in the environment. According to Hallman and McClain (1999), telecommunications operators have traditionally applied static models such as the total element long-run incremental cost (TELRIC) model or net present value (NPV) for conducting network infrastructure investment cost-benefit analysis. Hallman and McClain (1999) describe the TELRIC model as one that relies on the discounted cash flow (DCF) method for reflecting the NPV of an investment in the local network.

The main levers in the TELRIC calculation are identified as follows (Jamison, 1999: 58-59): capital expenditure, operating expenses, cost of capital and depreciation. According to Hallman and McClain (1999: 145), TELRIC methods have the following shortcomings: prices, output levels and expenses are assumed to remain static over time; investments are assumed to be one-time with static factor 
prices, constant capacity, no differentiated risk, and no real options; assumption that there are no competitive impacts or market share losses due to changes in price; rate-based calculations are without dynamics, including input and output price, and discount and interest rate dynamics; there are no economies of scale or scope, no technological substitution, and no factor price considerations in TELRIC's engineering design and relationships; quantities do not rely at all upon demand elasticities or market shares, and are constant throughout time; and, depreciation is based on accounting methods that allocate costs arbitrarily over time, do not calculate economic depreciation, and include depreciation improperly in pricing formulas.

Hallman and McClain (1999) further state that the TELRIC methodology tends to oversimplify the investment decisionmaking process because it does not accurately reflect the investment decisions that telecommunications firms face when evaluating network build opportunities. These shortcomings of traditional TELRIC-based or DCF investment valuation techniques become more apparent when applied beyond network build costs, that is to layers where telecommunications applications and services are created and hosted (Athwal, Harmantzis \& Tanguturi, 2005). Cellular telecommunications operators worldwide are assessing the benefits of evolving towards next-generation service-oriented architectures (Pollet et al., 2006). According to Dai et al. (2000), these flexible architectures create options and opportunities that did not exist previously, and thus need to be evaluated.

\section{Purpose of the study}

The purpose of this study is to examine the application of real option valuation technique in cellular telecommunication industry in South Africa. This study aims to overcome all or some of the limitations of traditional investment valuation techniques like TELRIC model discussed above. Put differently, the aim of this study is to examine whether real options valuation techniques can be used by cellular telecommunications operators when making capital investment decisions in next-generation serviceoriented architectures. Therefore, this study aims to examine the use of non-probabilistic and probabilistic valuation techniques based on real options in assessing the value of probable future opportunities and benefits provided by the next-generation service-oriented architectures investments.

\section{Significance of this study}

According to Pollet et al. (2006), the cellular telecommunications industry is characterized by fierce competition, amidst ever changing consumer preferences and rapidly evolving technology. Pollet et al. (2006) suggest that cellular service providers have the option of avoiding a price-war confrontation on the same service offering, and considering a value-based offering. This comprises value creation through innovative services bundling (such as quadruple play - voice, messaging, data and video) combined with a differentiated tariff scheme. The anticipated result will be a reduction in customer dissatisfaction and improvement in average revenue per user (ARPU). They argue that the challenge for the cellular service provider is to maximize its value-capturing ability in delivering the value-added to the customer. This can be realized through various consolidation efforts in service delivery such as use of service convergence platforms, sometimes referred to as the service delivery platforms (SDP), improvement in operational efficiency, and reduction of time-to-market of new services through flexible deployments, such as the use of service-oriented architecture (Pollet et al., 2006; Sur, Skidmore \& Chakravarty, 2006).

It is envisaged that findings from this research will provide management in a telecommunications environment with a framework for making more informed decisions concerning which projects to invest in, how much to invest, and when to invest. This is anticipated because Mun (2006) believes that real options are useful as a strategic business tool in capital investment decisions. Mun (2006) advises that the approach should incorporate a learning model which will enable managers to make better and well-informed strategic decisions, amidst business conditions fraught with uncertainty and risk.

Alleman (2002) argues that management does not have to be locked into passive investment strategies, informed by traditional approaches in static cash flow estimation. The proposed real options analysis approach should provide a more dynamic investment planning model, adapting to changing technology and market conditions (Alleman, 2002). He referred to this dynamic investment strategy as the flexibility provided to management, which includes the option to defer, replace, expand or shut down a project capital investment. Therefore, the benefit of this study is to determine the usefulness of new investment analytics in valuing management flexibility, presented by strategic project options and the ability to alter initial operating strategies in delivering end-user services in a cellular telecommunications environment.

\section{Literature review}

Harmantzis and Tanguturi (2007) state that there are challenges that cellular operators face when making capital intensive investment decisions in new technology infrastructure on the core network. According to Harmantzis and Tanguturi (2007), there is uncertainty in the potential net benefit that new infrastructure investments could provide. They argue that there is an element of risk in the user adoption of new products and services. They further argue that the difficulty in valuing IT infrastructure investments is attributable not only to the project's potential to improve current operations, but also to the potential to allow innovation, and to provide a sustainable competitive advantage over time (Renkema, 2000 cited in Svavarsson, 2004). These propositions could be applied to the nextgeneration telecommunications services architecture investments in that the benefit accrues not only from the 
improvement in current service operations, but also from future opportunities to innovate.

Mun (2006) describes the process of valuing an investment on a time horizon made up of a shorter time period and longer time period (depicted in Figure 1 below). According to Mun (2006), traditional valuation techniques are best suited for shorter time frames that are somewhat deterministic. He states that, in the long term, strategic opportunities arise, and proposes a more appropriate investment valuation approach for the long term that incorporates new advanced analytics such as real options. This is a good suggestion because in the long term, it is harder to correctly estimate variables; hence management can create value by initiating and executing strategic options.

Project's total value is based on the DCF value and the strategic value. DCF analysis usually uses a combination of 12 months trailing (historical period) project financial data for the base year, project budget data for the following year and future cash follow forecasts usually for a period not exceeding 5 years (budget forecast horizon). New

investment analytics are best suited to forecast returns in the strategic period, that is usually beyond the fifth year. Conceptually, the total value of an investment is made up of two components: the traditional (static or passive) NPV of expected cash flows, and the option value of operating and strategic adaptability (Trigeorgis, 1999). This can be represented by an expanded NPV analysis formula as follows (Trigeorgis, 1999:4):

$\mathrm{ENPV}=\mathrm{PNPV}+\mathrm{VOA}$

where:
$\mathrm{ENPV}=$ Expanded (Strategic) NPV,
PNPV = Static (passive) NPV of expected cash flows, and
VOA $=$ Value of options from active management (Value of operating \& strategic adaptability or flexibility)

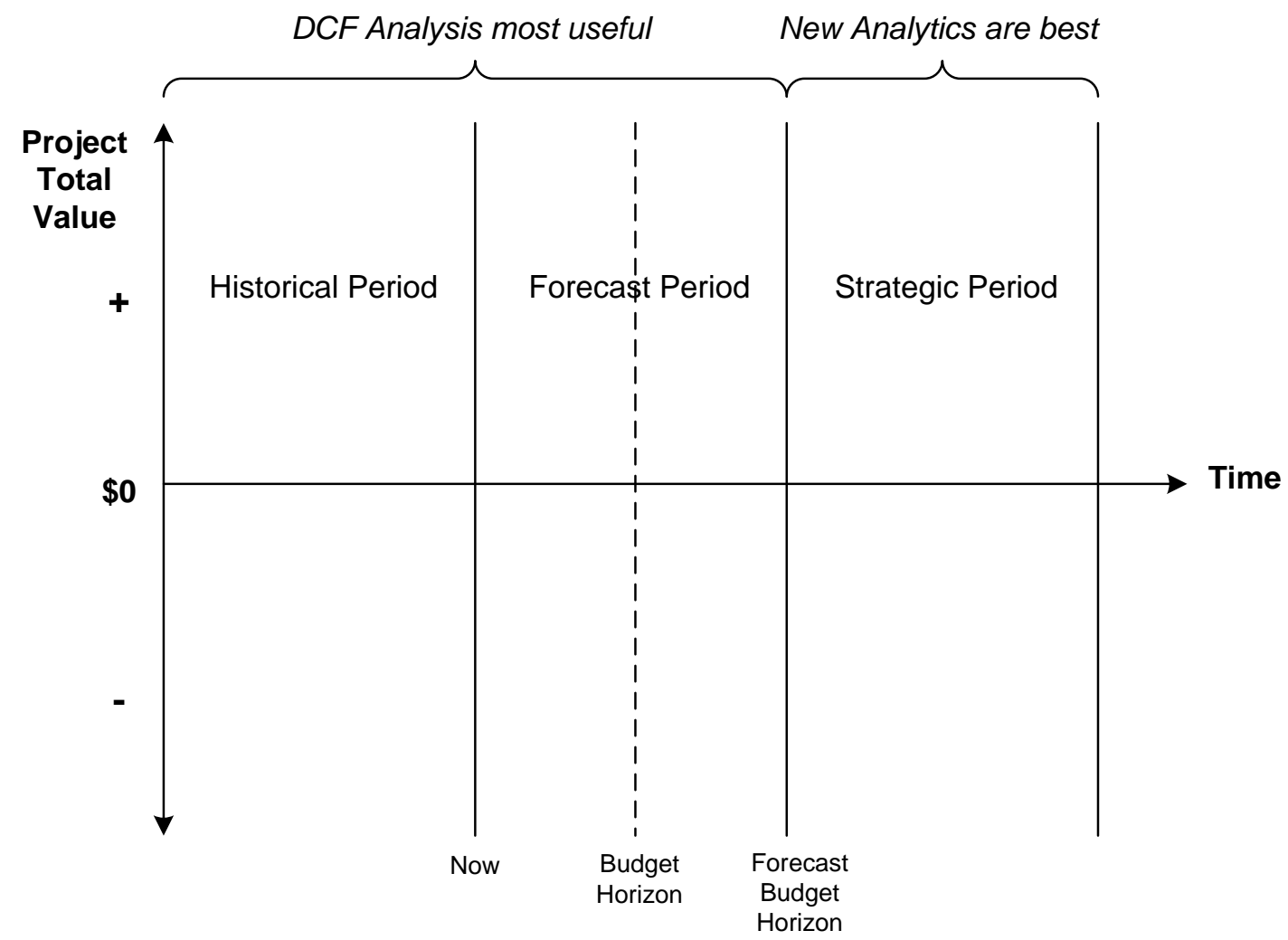

Figure 1: Traditional versus new analytics

Source: Mun (2006: 73)

According to Ekstrom and Bjornsson (2003), nonprobabilistic valuation methods such as discounted cash flow (DCF) and qualitative methods have, in the past, proved popular amongst decision makers. Managers are often faced with the challenge of having to assess the value of pursuing certain project opportunities (Shepherd, 1999 and Bharadwaj \& Tiwana, 2005 cited in Tiwana, Wang,
Keil \& Ahluwalia, 2007), but the lack of structured information often leads to significant uncertainty in decision making. Some managers often rely on discounted cash flow (DCF) techniques for project valuation. DCF methods include net present value (NPV) and internal rate of return (IRR) in guiding investment decisions. In their application, for an investment to be deemed profitable, NPV must be 
greater than 0. Dixit and Pindyck (1995) explain how the NPV rule simply provides management with a basic accept or do-no-accept decision recommendation. However, the shortcoming of classical valuation methods such as DCF is that they do not reflect the value of future strategic options (VOA). Dixit and Pindyck (1995) argue that options are opportunities (rights), but not obligations. They add on saying that these rights provide management with flexibility, and hence options have value associated with them.

Thinking on real options has cautioned the failure to account for flexibility, which the DCF technique ignores (Tiwana et al., 2007). Flexibility allows managers to create and exploit future strategic opportunities (Perlitz, Peske \& Schrank, 1999; Balasubramanian, Kulatilaka \& Storck; 2000 and Bowman \& Moskowitz, 2001 cited in Tiwana et al., 2007). According to Dos Santos (1991) cited in Ekstrom and Bjornsson (2003), classical valuation methods are not suited for accounting for management flexibility. More specifically, the NPV rule disregards various future options available for a project when considering a capital investment decision, such as the option to expand, option to delay, and option to abandon if market conditions become pessimistic. In support of Ekstrom and Bjornsson (2003), Svavarsson
(2004) argues that because DCF valuation assumes a fixed investment strategy and a constant required rate of return, it is not suitable for valuing future opportunities such as the option to expand an IT platform investment, thus exploiting new applications that the expansion would provide.

Alleman (2002) suggests that a real options methodology can be developed by taking the best features of DCF and decision tree analysis (excluding their weaknesses) when valuating management flexibility and strategic options in real assets. Decision tree analysis (DTA) addresses multiple possible outcomes. Using an option-based or expanded-DCF is a possibility (Trigeorgis, 1996 cited in Alleman, 2002). DCF models can be extended to incorporate flexibility in investments, and used as an alternative to real options (Jong, Ribbers \& Zee, 1999 cited in Ekstrom \& Bjornsson, 2003). Dai, Kauffman and March (2000) suggest using the expanded NPV (extended DCF) method for valuing the option-inclusive value of the project. The expanded NPV method is defined as the sum of the traditional NPV and the expected value of future projects made possible by the initial investment. Figure 2 (below) illustrates the expanded NPV method.

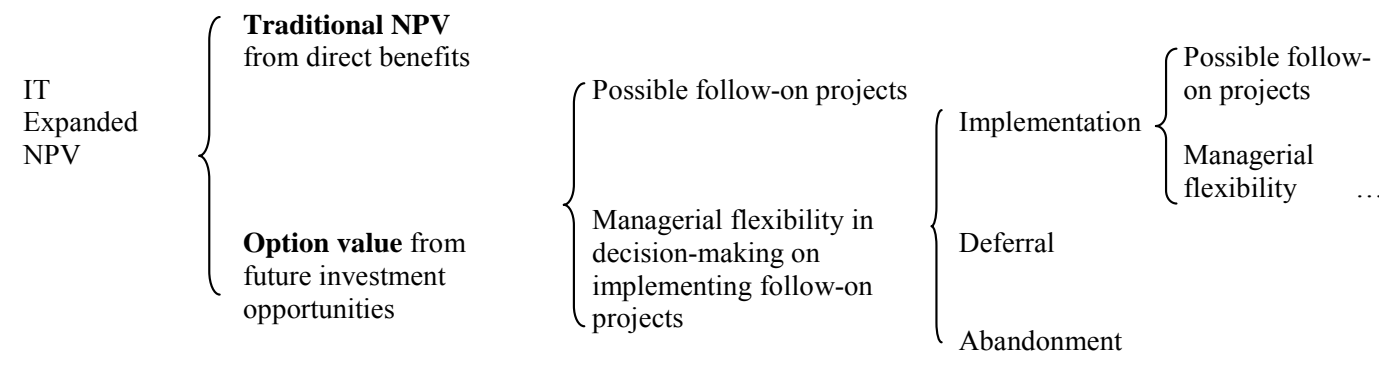

Figure 2: Option-inclusive value of an IT project

Source: Dai, Kauffman \& March (2000: 4)

In other words, the expanded NPV (illustrated in Figure 2 above) for IT projects comprises the sum of traditional NPV (obtained through DCF) and the value of embedded options provided by the initial infrastructure or technology investment. The embedded options provide management with strategic flexibility for future project expansion, deferral or abandonment. Follow-on projects in the form of compound options (options-on-options) are also possible.

The pricing model used for financial options can generally be mapped to real options (Harmantzis \& Tanguturi, 2007), but Tiwana, Keil and Fichman (2006) argue that the absence of a traded market for IT assets can lead to difficulty in estimating options parameters. Valuation of real options applies to the option to expand, defer, contract, abandon, switch use, or alter a capital investment (Panayi \& Trigeorgis, 1998). Ross, Westerfield and Jordan (2003) give an example of an application of real options analysis in the construction industry. They explain that the future price of an important construction material required for a project may be uncertain, relative to today's price of the material.
They state that, if the future price of the material is likely to be higher than today's price, the option available to the contractor is to buy the material at today's price. They estimate the value of the option, in crude terms, as being the difference between the future price of the material (market price) and today's price (exercise price). The cost of the option would be the premium the contractor would have to pay the supplier to secure the right to buy or not to buy the material in future at today's prices, depending on what the future price is (Ross et al., 2003).

The analysis made by Ross et al. (2003) in the construction industry makes it seem probable that the same approach could be applied to capital investment analysis of nextgeneration service architectures in the telecommunications industry. Construction and the telecommunications industry are two different industries, but similar in their requirement for high capital investment in infrastructure, the former is characterized by uncertainty in future material prices, the latter characterized by uncertainty in future technology adoption and demand by the industry, thus influencing 
prices (Arboleda \& Abraham, 2006). In the telecommunications industry, the cost of the option could be equivalent to the deposit or premium the cellular telecommunications operator would have to pay to secure the right to implement new technology or evolve the current service delivery architecture to next-generation architecture in future at today's prices (Yu, Lee \& Chang, 2005). Consequently, the deposit or premium would essentially give the cellular telecommunications operator the right, and not the obligation to expand or defer the investment in future.

'Thinking of investments as options substantially changes the theory and practice of decision making about capital investments' (Dixit \& Pindyck, 1995:1). According to Anderson (2000), there is a growing interest in using real options to guide capital budgeting and strategic decisions in dynamic environments. Anderson (2000) argues that the options approach provides a more proactive assessment of future business opportunities and adaptability under uncertainty. Tiwana et al. (2006) claim that a real options approach enables more accurate valuation of capital investments. Real options have been tested empirically to evaluate IT investments such as object-oriented middleware platforms (Dai et al., 2000). Furthermore, real options have been applied in valuations in various industries such as pharmaceutical, energy, mining and information technology (Schwartz \& Trigeorgis, 2001; Mun, 2002; Trigeorgis, 1996 cited in Harmantzis \& Tanguturi, 2007).

Alleman (2002) mentions that, although real options theory has been increasingly applied in other industries, its application in the telecommunications industry has been very limited. Athwal, Harmantzis and Tanguturi (2005) explain that the low usage of real options valuation method is as a result of the fact that this valuation method is relatively new in the telecommunications industry as a whole. Despite that, Alleman (2002) and Athwal et al. (2005) showed that real options could be helpful to the telecommunication industry for strategic evaluation, estimation and cost modelling. A survey conducted by Tiwana et al. (2007:158) in 88 firms revealed an interesting insight in management's application of real options. It was found that managers are less likely to apply real options in projects where the NPV already exhibits an adequate value by the traditional NPV estimate. Tiwana et al. (2007) labelled this phenomenon 'the bounded rationality bias'. This would imply that management's perception of the benefit of real options analysis is in projects where the NPV is negative or marginal (Tiwana et al., 2007).

According to Dai, Kauffman and March (2007), IT infrastructure investments create growth options which can be evaluated using options analysis. Based on findings from Trigeorgis (1996), Alleman (2002) and Dai et al. (2007), it would seem plausible that real options valuation could be extended to valuing investments in next-generation telecommunications service architecture implementations such as SOA and SDP that integrate the IT and telecommunications domains. In that context, the flexibility provided by SOA in developing and integrating business applications, and the strategic options or opportunities that SDPs provide in delivering new and innovative services to subscribers, represent embedded options and choices inherent in open standards architecture implementations (Pollet et al., 2006). The flexibility provided to management includes the option to defer, switch, replace, expand and grow, abandon, shut down, restart and contract (Alleman, 2002). Carlsson and Fuller (2002) suggest that project analysts should follow a real option rule that compares the option to invest today with the option to wait (to defer the investment) when making an investment decision. When deferring an investment, the question is for how long should it be postponed (Carlsson \& Fuller, 2002).

According to Bowman and Moskowitz (2001), users of real options models should understand the quantitative aspects of these models, and may often need to create a customized model for each situation. They argue that if this is not done, the assumptions used in standard option valuation models could conflict with the conclusions reached through strategic analysis. Consequently, this would suggest that proposing the development of a customized real options valuation for application in the context of the research problem is recommended. Benninga and Tolkowsky (2002) state that, in considering real options for project valuation, the nature of options available to the manager need to be fully understood. For example, when abandoning a project is an option, the costs of abandonment need to be considered.

Harmantzis and Tanguturi (2007) used the Black-Scholes valuation model in assessing two cases in a wireless industry; Case A being the option to defer expansion of $2.5 \mathrm{G}$ to $3 \mathrm{G}$ wireless network, and Case $\mathrm{B}$ being the option to expand a $2.5 \mathrm{G}$ network to WLAN (as an alternative to $3 \mathrm{G}$ ). Athwal et al. (2005) used the Black-Scholes option pricing model in valuing the replacement of centric voice services with hosted Voice over Internet Protocol (VoIP) services. In a similar approach, the Black-Scholes model could be proposed for valuing the investment a cellular telecommunications operator plans to make in nextgeneration service architectures, characterized by uncertainty in future prices, relative to current prices, which affect the investment value. The Black-Scholes model has been applied in numerous cases for valuing simple or singlestage options, based on single call options, such as the option to expand or replace (Benninga \& Tolkowsky, 2002; Sheppard, 2003; Svavarsson, 2004; Harmantzis \& Tanguturi, 2007). A single stage may have multiple periods, for example, years. This is in contrast to compound or multistage options where each subsequent stage is dependent on the previous stage. Anderson (2000) indicated that the Black-Scholes model could be used for valuing compound call options as well. However, Benninga and Tolkowsky (2002) caution that the use of a Black-Scholes model in a real options framework only gives an approximation to the option value intrinsic in the real options.

The binomial lattice decision analysis method can be used for assessing more complex compound options, that is options to expand, defer, abandon, or contract throughout multiple stages of a project (Anderson, 2000; Svavarsson, 
2004). Benninga and Tolkowsky (2002) discuss the possible application of the binomial lattice model in research and development (R\&D) project valuation such as biotechnology projects in the pharmaceutical industry. Svavarsson (2004) developed a binomial lattice model using a risk neutral probability approach for valuing real options in strategic IT platform investments. The model was used for the evaluation of strategic flexibility in the investment and, quantifying and managing the associated risks. Svavarsson (2004) describes the strategic IT platform investments in and ERP project as being characterized by four stages, namely Financial Management system (FM) pilot, FM full implementation, Project Management system (PM) pilot, and PM full implementation, with each stage having its own investment uncertainty such as user adoption and technological risk. Implications are that, because nextgeneration telecommunications service-oriented architectures are typically executed in multiple stages, similar to strategic IT platform investments projects mentioned above, the binomial lattice model could be developed for real option valuation of next-generation telecommunications service architectures.

\section{Data and data manipulation}

The limited number of cellular telecommunications operators in South Africa, and the context of this study being on valuing next-generation mobile services architecture implementations, mean that little or no historic data exists for doing comparative analysis in project implementation. The cellular network operator assessed in this instance has recently been considering investing significant capital in a new services oriented architecture (SOA) and a service delivery platform (SDP) in order to achieve operational efficiencies and maximize its value capturing ability for this study. A quantitative case study research approach is necessary to achieve the required financial modelling exercise.

While at the time of this study, in the South African context, there may have been some variability in the incumbent operator's capability and strategic flexibility to implement a next generation messaging (NGM) platform within a SOA framework, this exclusivity would not apply in a global context, as similar implementations have been done before, according to findings by Pollet et al (2006). Other mobile operators in other parts of the world are arguably in a similar position as the incumbent operator in South Africa in that they also have SOA implementations for delivering mobile services, and some have acquired the NGM infrastructure. For example, in Africa, Mascom in Botswana and Cell One in Namibia have invested in the NGM infrastructure.

The incumbent operator (case site) considered in this study is the only cellular operator in South Africa with the telecommunication SOA and next-generation messaging (NGM) platform implementation. For quantitative analysis, a combination of service-oriented architecture (SOA) and service delivery platform (SDP) projects that require significant capital investment are selected for this study. The suitability of such projects for real options valuation rests in their inherent risk in implementation, uncertainty in future cash flows, and flexibility in their implementation. The new architecture design presents options for future system expansion and delivery of new consumer products and services.

In 2005, the cellular operator considered in this case analysis, initiated the migration of its legacy middleware services architecture to a more flexible service-oriented architecture (SOA) for providing cellular telecommunications services such as billing, self-service and other business support services. The main driver for the architecture migration was the business focus on realizing operational efficiencies in service delivery. In fourth quarter 2006, the operator procured a next-generation messaging platform (NGM). The NGM platform is a telecommunications service delivery platform (SDP), offering the cellular operator the capability to host both $2 \mathrm{G}$ and $3 \mathrm{G}$ voice-centric services such as voicemail (VMS), interactive voice response (IVR), video messaging and other consumer services such as ring-back tones (RBT). The main drivers behind the NGM platform investment at the time were capacity requirements due to subscriber growth, and for decreasing operating costs. The existing legacy voicemail system (eZoner) was expensive to maintain due to its old proprietary architecture, and offered no flexibility in consumer service deployment.

The historical capital budgeting data on the NGM project was obtained. Where necessary, financial cash flow forecast was done using established time series forecasting techniques. However, Ekstrom and Bjornsson (2003) caution that the costs and benefits associated with IT investments are uncertain and difficult to measure. The template structure (refer to Appendix A.1) was used in collecting the project cash flow data and calculating the project DCF (traditional NPV). In modelling the next generation messaging (NGM) project cash flow, capital budgeting data, comprising cost of infrastructure acquisition, project implementation, system integration, operation and maintenance, was used. A basic service provided by the NGM system is voicemail. Inbound voicemail deposits to the system generate revenue for the mobile operator. The migration from the legacy eZoner system to NGM would result in the preservation of this basic service, so the historical revenue data generated by the eZoner system during the period starting from January 2008 to June 2008 was used as a basis for estimating the 2008 revenue forecast for the NGM system. The 2008 inbound voicemail revenue data was used as a basis for revenue extrapolation for the period 2009 to 2011, having adjusted for subscriber growth and projected service uptake. The assumption made was that service uptake would be proportional to subscriber growth. The validity of the assumption is supported by the service provisioning process. The service is by default provided during subscriber account activation.

A one and half year history of the NGM project financial data (actual cash outflows and calculated cash inflows) was 
collected, and a three year budget forecast was estimated to model the five year discounted cash flow. Other market data were collected from the following reliable sources: South African National Treasury, Statistics South Africa, Annual reports of the incumbent operator and comparable companies, Bond Exchange of South Africa, South African Reserve Bank, Damodaran's website (2008), and OMX (Aktiebolaget Optionsmäklarna/Helsinki Stock Exchange) Nordic Exchange.

The next-generation messaging (NGM) project is considered a high risk project due to its radical, new system architecture design and, being the first of its kind to be implemented in a South African mobile operator environment. Due to the perceived high project risk and operational risk, the projectspecific hurdle rate is assumed to be higher than the firmspecific weighted average cost of capital (WACC). Following the approach suggested by Ross et al. (2003) to use an adjusted discount rate where the project's risk profile deviates from the firm's risk, a risk-adjusted project-specific hurdle rate was used as the discount rate for the project cash flow.

The firm's hurdle rate is calculated as follows:

$\mathrm{WACC}=\mathrm{w}_{\mathrm{e}} \cdot \mathrm{K}_{\mathrm{e}}+\mathrm{w}_{\mathrm{d}} \cdot \mathrm{K}_{\mathrm{d}}(1-\mathrm{tc})$

where:

tc $=$ Marginal (corporate) tax rate of $28 \%$ in South Africa (Budget Speech, 2008),

$\mathrm{K}_{\mathrm{e}} \quad=\quad$ Cost of equity,

$\mathrm{K}_{\mathrm{d}} \quad=\quad$ Pre-tax Cost of debt, and

$\mathrm{w}_{\mathrm{e}}$ and $\mathrm{w}_{\mathrm{d}}=$ Market value weights of equity and debt, respectively.

Note : The cellular network operator considered in this study had no preferred equity capital at the time of this analysis

Given that the cellular operator is a private entity, the market values of debt and equity were unavailable to establish the market value weights $\left(w_{e}\right.$ and $\left.w_{d}\right)$. To overcome this, the South African telecommunication industry average debt-to-equity $(D / E)$ ratio is calculated, from which the market value weights $\left(w_{e}\right.$ and $\left.w_{d}\right)$ were estimated as described in equations 3 and 4 (below). The assumption made is that the cellular operator in this study, operating in the South African context, would tend towards a debt ratio similar to the industry average of comparable firms (in characteristics, not market capitalization size), as the company matures. This is in line with Damodaran's (2002) suggestion that when a private firm is being valued for an initial public offering (IPO), we could assume that the company would structure its debt policy to resemble that of comparable firms.
Using the industry average Debt /Equity $(D / E)$, the debt ratio $(\delta)$ or market weight of debt can estimated as follows:

$\delta$

$$
\begin{aligned}
& =\frac{\mathrm{D}}{\mathrm{D}+\mathrm{E}} \\
& =\frac{\mathrm{D} / \mathrm{E}(\%)}{100+\mathrm{D} / \mathrm{E}(\%)}
\end{aligned}
$$

and, from deduction;

$\mathrm{w}_{\mathrm{d}} \quad=1-\mathrm{w}_{\mathrm{e}}$

The cost of debt measures the current cost to the firm of borrowing funds to finance projects (Damodaran, 2002). In an emerging market firm, the cost of debt comprises the risk free rate, the company default spread (risk) and the country default spread (risk). Since the operator is operating in an emerging market, that is in the Republic of South Africa, the pre-tax cost of debt $\left(\mathrm{K}_{\mathrm{d}}\right)$ is based on the risk free rate $\left(\mathrm{R}_{f}\right)$, the company's default spread (which is driven by the company's bond rating and the country default spread).

Therefore:

$\mathrm{K}_{\mathrm{d}} \quad=\mathrm{r}_{\mathrm{f}}+$ Company default spread

+ Country default spread

where:

$\mathrm{r}_{\mathrm{f}}$

$=$ Risk free rate

$\approx$ Default-free government bond rate, or

$\mathrm{r}_{\mathrm{f}}$

$=($ S.A Government 5 yr retail Bond Rate

- Default spread adjustment)

The cost of equity $\left(\mathrm{K}_{\mathrm{e}}\right)$ measures the corporate equity risk and is calculated as shown in equation 6 below:

$\mathrm{K}_{\mathrm{e}} \quad=\mathrm{r}_{\mathrm{f}}+\beta$ (Total Equity Risk Premium)

where:

Total Equity Risk Premium

$=\mathrm{R}_{\text {Mature market equity risk premium }}$

$+\mathrm{R}_{\text {Country risk premium }}$

$\mathrm{R}_{\text {Mature market equity risk premium }}$

$=$ United States Equity Risk Premium,

$=4,79 \%$ (at the time of analysis), 
and $\mathrm{R}_{\text {Country risk premium }}$

$$
=1,2 \% \text { (at the time of analysis) }
$$

Given the fact that the operator is a private entity, regression beta for the undiversified risk cannot be estimated as the market price returns are unavailable. It is expected that this risk will be higher due to the entire investment being tied in the business, and is undiversified. The bottom-up approach is used to estimate the levered beta ( $\left.\beta_{\text {private firm }}\right)$ of a private firm (Damodaran, 2002) as follows.

$\beta_{\text {private firm }}=\beta_{\text {unlevered }}[1+(1-\mathrm{tc})($ Industry average

where:

$\beta_{\text {private firm }}=$ the beta of levered firm,

$\beta_{\text {unlevered }}=$ the beta of unlevered firm,

tc $=$ the South African corporate tax rate of $28 \%$ (at the time of analysis), and

$\mathrm{D} / \mathrm{E} \quad=$ the debt-to-equity ratio.

According to Damodaran (2002), the beta of a private firm can be calculated as follows:

$\beta_{\text {private firm }}=\frac{\beta_{\mathrm{m}}}{\rho_{\mathrm{i}, \mathrm{m}}}$

where:

$\beta_{\mathrm{m}} \quad=$ average regression beta across publicly traded comparable firms, and

$\rho_{\mathrm{i}, \mathrm{m}}$

$=$ correlation between the private firm and the market.

Damodaran (2002) added on saying that the total (private firm) beta will be higher than the market beta if the correlation is lower and vice versa. Damodaran (2002) continued to argue that, in other to compute the relative standard deviation of the private firm and, if the standard deviation of a private firm is scaled against the market index's standard deviation to yield what is known as a total beta, one can simply divided beta of a private firm by the correlation. This procedure is followed in this research to compute the standard deviation of a case study because a case study for this research is a private firm (refer research methodology below).

\section{Research methodology}

Creswell (2003) describes quantitative research as being based on post positivist knowledge claims, where a process of experimentation or surveys for numeric data collection on predetermined instruments is used to test the theories, explanations and hypotheses and, to evaluate certain variables, using statistical procedures. This model is commonly known as a post positivist model. In line with this description, analytical financial models for discounted cash flow analysis and real options analysis will be applied for evaluating capital investment projects based on serviceoriented architectures at a cellular network operator in South Africa. The quantitative research design proposed for this study follows a very similar process used by Sheppard (2003) where a base case for a capital investment project is evaluated. Traditional DCF analysis will be used for evaluating the base case. Additionally, sensitivity analysis where there is uncertainty in future cash flows will be conducted. The DCF analysis method will be extended to assess the impact of project implementation risk on the investment.

Athwal, Harmantzis and Tanguturi (2005) took the approach of first calculating the NPV of a centrex PBX telephony solution replacement project for a 5-year period, and then used derivatives theory to value the option of the investment. In a similar approach, this study will undertake to quantify the total investment value of the next-generation messaging (NGM) platform investment, taking into account the static NPV and embedded options provided by the new generation architecture (illustrated in Figure 3 below).

The next-generation messaging (NGM) system is the service delivery platform (SDP) layer that is logically depicted in Figure 3 above. The NGM system provides a series of single-stage simple options. The service-oriented architecture (SOA) layer provides more complex, multistage compound options in the form of re-usable components, (commonly known as web-services -WS).

Real options analysis will be used to evaluate the case where future project growth options exist, such as the option to expand or defer, with the associated uncertainty in future cash flows. The investment valuation process as suggested by Mun (2006:107) is summarized as follows: qualitative project screening, base-case project cash flow projections, base-case project traditional DCF analysis, risk analysis using the real options valuation, and decision analysis. The project valuation process is made up of several phases as suggested by Mun (2006). One of these phases is a qualitative project selection process, where a business case for each of the shortlisted projects will be formulated, using traditional DCF analysis. Then risk identification and risk analysis is recommended (as is the case for new technology considered in this study). Embedded options are assessed to determine the project's strategic value. As a result, a decision is made based on a combination of several factors such as project net worth and risk exposure.

According to Tiwana, Keil and Fichman (2006), real options analysis entails the determination of the active NPV $\left(\mathrm{NPV}_{\text {active }}\right)$ of the project, which is equal to the traditional or passive NPV of the project $\left(\mathrm{NPV}_{\text {passive }}\right)$ plus the value of managerial flexibility, the latter being the function of the value of the bundle of options embedded in the project. 


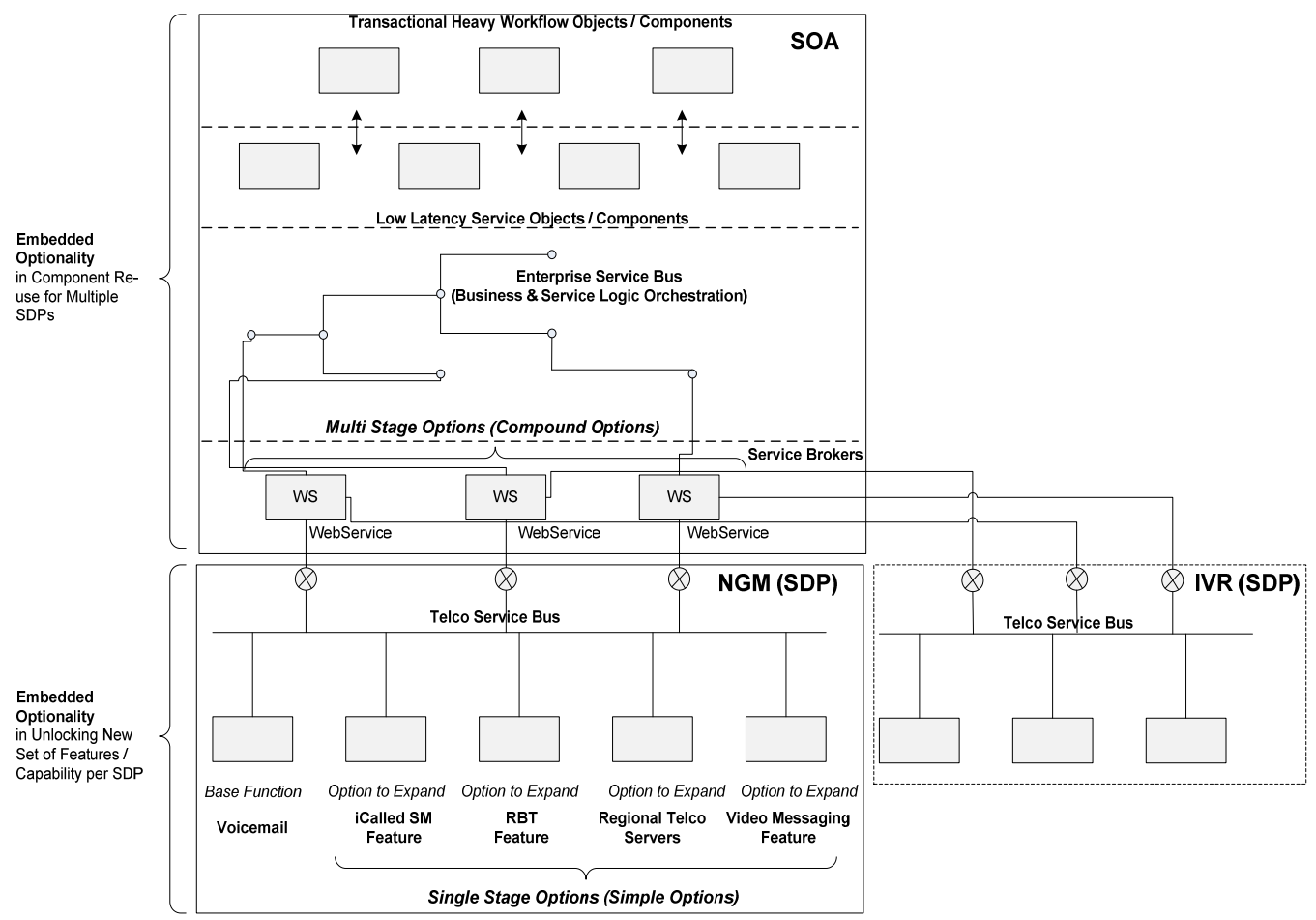

Figure 3: Detailed model of the next-generation telecommunications service architecture illustrating strategic flexibility provided by embedded options

Source: Pollet, Maas, Marien \& Wambecq (2006: 531) [Adapted and applied to a cellular operator's services architecture]

Therefore,

$\mathrm{NPV}_{\text {Active }}=\mathrm{NPV}_{\text {passive }}+f($ real options value $)$

where:

$\mathrm{f}$ (real options value) is the value of the bundle of real options embedded in the project), and $\mathrm{f}$ (real options value) is modelled (below).

Tiwana et al. (2006) argue that the true value of a project $\left(\mathrm{NPV}_{\text {Active }}\right)$ where $\mathrm{NPV}_{\text {passive }}$ is equal to 0 , would be equal to the total value of the various real options embedded in the project. Management would traditionally be reluctant to invest in this project, from a passive $\left(\mathrm{NPV}_{\text {passive }}\right)$ standpoint, but it could still be worthwhile when the additional value from real options is considered. Mun (2006) applied real option analysis to several real-life applications, such as high 'tech' manufacturing and in the biopharmaceutical industry, using super lattice solver and risk simulator software. In a similar approach, valuation of capital investment in a nextgeneration messaging architecture project at a cellular network operator is conducted in this study, with the aim of determining their effectiveness. The required inputs into the proposed quantitative financial models will be a combination of historical and forecast project budget data in estimating the passive NPV, and expected project financial data based on future options driven by strategic opportunities and management flexibility (as illustrated in Figure 2 above).

\section{Research procedures}

As shown in Figure 3 (above), the next generation telecommunications service architecture implementation specific to the incumbent operator presents a series of simple single-stage options and multi-stage compound options provided by design re-use. The total investment value is calculated as follows:

Total Project Investment Value $=\mathrm{NPV}_{\text {passive }}$

+ Strategic Opportunities $\mathrm{SOA}+\mathrm{SDP}(\mathrm{NGM})$

The strategic opportunities (options to expand) are nonmutually exclusive, and are ranked according to their strategic priority to the company, as illustrated in Table 1 below.

The strategic opportunity (that is, the option to expand the NGM platform) is given a priority number 1 ranking in Table 1 (above). The strategic opportunity is more precisely referred to as the value of operating flexibility (as illustrated in Figure 4 below). This is the cost saving opportunity to the company by realizing future operational efficiencies through capacity license management. 


\section{Procedure 1: Black-Scholes Model}

The Black-Scholes model makes use of an option pricing formula. The European call option is calculated using the generalized Black-Scholes model as follows (Mun, 2006:124) :

Call $=\mathrm{Se}^{-\mathrm{q}(\mathrm{t})} \Phi\left[\frac{\ln (\mathrm{S} / \mathrm{X})+\left(\mathrm{rf}-\mathrm{q}+\sigma^{2} / 2\right) \mathrm{t}}{\sigma \sqrt{\mathrm{t}}}\right]-\mathrm{Xe}^{-\mathrm{rf}(\mathrm{t})} \Phi\left[\frac{\ln (\mathrm{S} / \mathrm{X})+\left(\mathrm{rf}-\mathrm{q}-\sigma^{2} / 2\right) \mathrm{t}}{\sigma \sqrt{\mathrm{t}}}\right]$

where:

$\mathrm{q}=$ the dividend. The other inputs are defined in Table 2 (below).
Table 1: Priority ranking of options to expand the NGM system

\begin{tabular}{l|c}
\multicolumn{1}{c|}{ Strategic Opportunity (Option to Expand) } & $\begin{array}{c}\text { Priority } \\
\text { Ranking }\end{array}$ \\
\hline $\begin{array}{l}\text { Capacity Demand Management } \\
\text { (Call Completion Service (iCalled SM)) }\end{array}$ & 1 \\
\hline $\begin{array}{l}\text { Network Element Consolidation } \\
\text { (SS7 or SIP Interactive Voice Response (IVR) }\end{array}$ & 2 \\
Application) & 3 \\
\hline $\begin{array}{l}\text { IT Architecture Consolidation } \\
\text { (SOA Architecture Migration from Comptel) }\end{array}$ & 4 \\
\hline $\begin{array}{l}\text { Network Efficiency } \\
\text { (Regional Telco Servers (2G/3G Media Servers)) }\end{array}$ & \\
\hline $\begin{array}{l}\text { New Revenue Stream } \\
\text { (Ring-back Tone (RBT) and Video Messaging }\end{array}$ & 5 \\
\hline Application) &
\end{tabular}

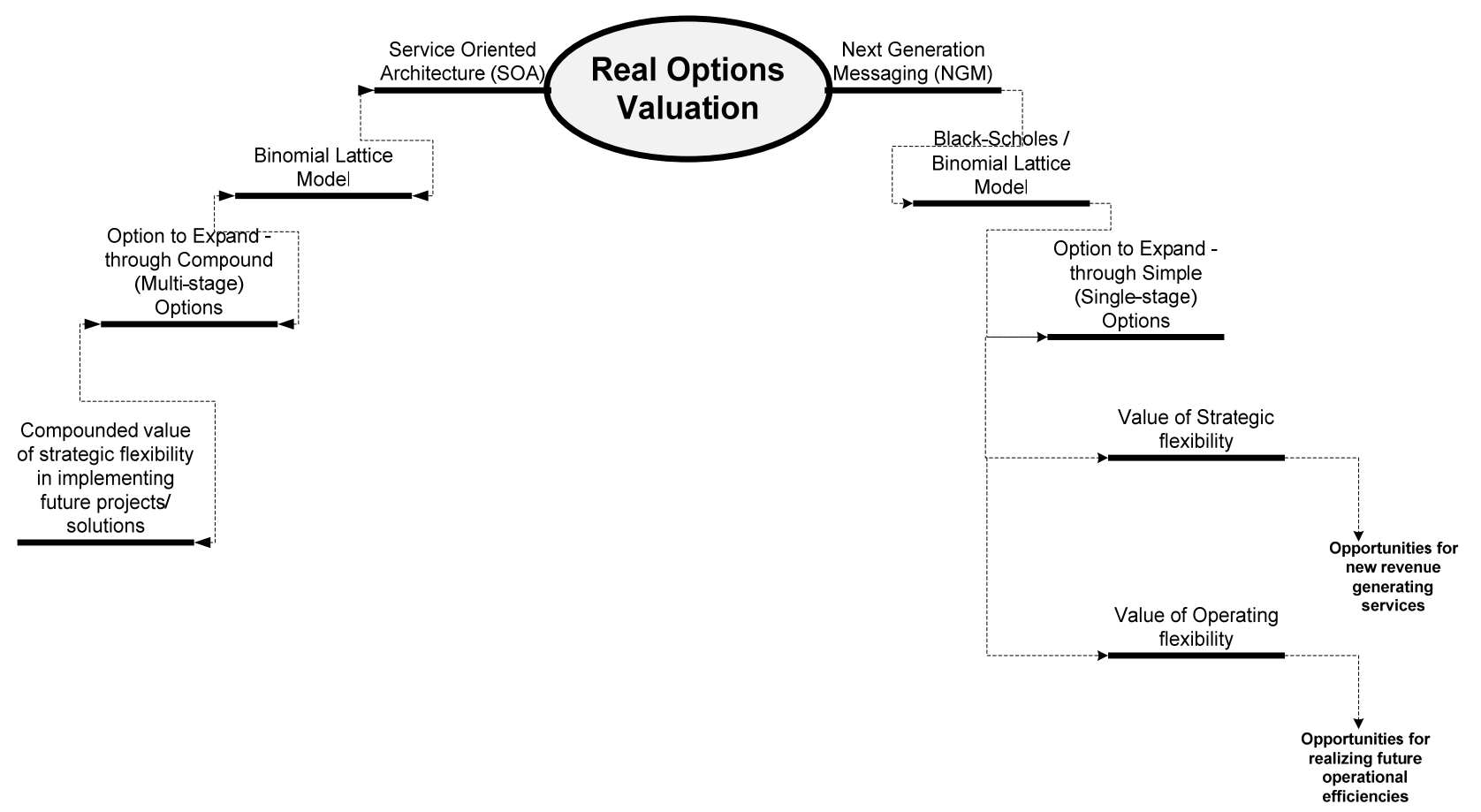

Figure 4: Mind-map representation of the proposed real options valuation model for next-generation telecommunications and service-oriented architectures

Source: Mun (2006: 124,186) [Adapted and applied to SOA and NGM architecture valuation]

In this application of real options analysis, it is assumed that no dividends are payable, therefore equation (11) is rewritten as follows (Mun, 2006:147):

Call $=\mathrm{S} \Phi\left[\frac{\ln (\mathrm{S} / \mathrm{X})+\left(\mathrm{rf}+\sigma^{2} / 2\right) \mathrm{t}}{\sigma \sqrt{\mathrm{t}}}\right]-\mathrm{Xe} \mathrm{e}^{-\mathrm{rf}(\mathrm{t})} \Phi\left[\frac{\ln (\mathrm{S} / \mathrm{X})+\left(\mathrm{rf}-\sigma^{2} / 2\right) \mathrm{t}}{\sigma \sqrt{\mathrm{t}}}\right]$

where:

$\Phi=$ the cumulative standard normal distribution.

The inputs to the above-mentioned call option are defined in Table 2 (below). This table maps project investment growth opportunities and financial (stock) options.
Athwal, Harmantzis and Tanguturi (2005: 13) made the following assumptions regarding the option parameters: the value of the underlying asset or the current price $(\mathrm{S})$ is equal to the present value of cost savings realized when a new system is deployed; the investment cost $(\mathrm{X})$ is the strike price; the maturity of the option $(\mathrm{T})$ is the life of the project; for the risk or volatility $(\sigma)$, the historical stock price of movements of hardware vendor providers could be used; and, when valuing hosted Voice-over-Internet Protocol (VoIP) service networks, the standard estimate risk-free rate $\left(\mathrm{r}_{\mathrm{f}}\right)$ applied by several VoIP hosted service providers could be used. The Black-Scholes method is used in this study for valuing simple (single stage) options such as options to expand the NGM platform. For the multi-stage options, the binomial lattice method is utilised. 
An option provides the right to buy or sell an asset at a strike/exercise price $(\mathrm{K})$ at or before the option expiration date/time (t), as illustrated in Figure 5 below. Considering a dividend-adjusted Black Scholes model (Damodaran, 2001: 368 ), the value of a call option can be estimated as follows:

Value of a call option $=\mathrm{Se}^{-\mathrm{yt}} \mathrm{N}\left(\mathrm{d}_{1}\right)-\mathrm{Ke}^{-\mathrm{rt}} \mathrm{N}\left(\mathrm{d}_{2}\right)$

where

$\mathrm{y}=$ dividend yield $=($ dividends $/$ current value of the asset $)$,

$\mathrm{N}\left(\mathrm{d}_{1}\right)=$ the risk that the option will end up in the money,

$\mathrm{d}_{1}=\frac{\ln \left(\frac{\mathrm{s}}{\mathrm{k}}\right)+\left(\mathrm{r}-\mathrm{y}+\frac{\sigma^{2}}{2}\right) \mathrm{t}}{\sigma \sqrt{\mathrm{t}}}$ and

$\mathrm{d}_{2}=\mathrm{d}_{1}-\sigma \sqrt{\mathrm{t}}$

Considering a dividend-adjusted Black Scholes model (Damodaran, 2001: 368), the value of a put option can be estimated as follows:

Value of a put option $=\mathrm{Ke}^{-\mathrm{rt}}\left(1-\mathrm{N}\left(\mathrm{d}_{2}\right)\right)-\mathrm{Se}^{-\mathrm{yt}}\left(1-\mathrm{N}\left(\mathrm{d}_{1}\right)\right)$

When valuing real options, in a scenario where options are not likely to be exercised early (prior to the expiration date) and no dividends are payable, then a dividend-protected options valuation approach can be assumed (Damodaran, 2001). The real options value of the iCalled SM option (a priority 1 ranking option as illustrated in Table 1) is calculated using the Black-Scholes method (refer equation 13 above). According to Athwal et al. (2005), an alternative method of estimating volatility $(\sigma)$ is to use the historical stock price movement of hardware vendor providers. In this instance, the supplier of the NGM hardware is listed on the OMX Nordic Exchange. The stock prices (S) is the estimated present value of the cash-flows (Capex savings). The strike price $(\mathrm{K})$ is the total cost towards the iCalled SM option.

\section{Procedure 2: Binomial Lattice Method}

According to Mun (2006), given the scenario where there is risk or volatility in the project cash flow, and there is an increasing level of uncertainty over time, a binomial lattice valuation model can be used to estimate the option value. The greater the uncertainty, the wider the lattice becomes and hence the higher the option value. It is proven that, with volatility in the project cash flow being equal to zero $(0)$, the binomial lattice valuation collapses into a DCF calculation. Mun (2006) states that the project risk or volatility $(\sigma)$ may remain constant over time, but the level of uncertainty increases over time at a factor of $(\sigma \sqrt{ } \delta \mathrm{t})$, that is, the level of uncertainty increases at the square root of time, and the more time passes, the harder it becomes to predict the future. It is worth noting that it is the uncertainty that drives the value of options in projects. A binomial lattice method is a type of open-form discrete simulation, as opposed to a Black-Scholes method (discussed above). Black-Scholes model is a closed-form valuation method representing a Brownian Motion stochastic process or continuous simulation. But as the discrete simulation steps get smaller and the price process becomes continuous, it can be shown that the binomial model option pricing model converges to a Black-Scholes option pricing model (Damodaran, 2002). The real options value of the iCalled SM option (a priority 1 ranking option as illustrated in Table 2) is calculated using the binomial lattice method.

In this method, cash flows of a project are represented as points on a lattice as illustrated in Figure 6 below.

The project revenue or cost saving (present value of underlying investment) at time zero is the first point on the lattice. The method calculates state-dependent present value factors and multiplies them with state-dependent cash flows.

The node of a tree is discounted by the relevant state price of the node. The NPV of the project is the sum of all the discounted cash flows, minus the initial cost (Benninga \& Tolkowsky, 2002).

According to Mun (2006), the valuation lattice is calculated using two steps. The first step is to calculate the binomial asset lattice. The binomial lattice calculation requires the up (u) and down (d) factors as in equation 15 (below), as well as the risk-neutral probability measure (p) in equation 17 below (Mun, 2006).

$$
\begin{aligned}
\mathrm{u} & =\mathrm{e}^{\sigma \sqrt{\partial t}} \text { and } \\
\mathrm{d} & =\mathrm{e}^{-\sigma \sqrt{\partial t}} \\
& =\frac{1}{\mathrm{u}}
\end{aligned}
$$

where:

$(\partial t)=$ the step size, and the step size is measured as follows:

$(\partial t)=\frac{\text { Time to Maturity of the Option }(\mathrm{yrs})}{\text { Number of Lattice Steps }}$

According to equation 15 above, the up factor is simply the exponential function of the volatility of the cash flow returns multiplied by the square root of time-steps. The volatility is an annualized value, multiplying it by the square root timesteps breaks it down into the time-step's equivalent volatility. The down factor is simply the reciprocal of the up factor. The higher the volatility, the higher the up and down factors, and the wider the lattice becomes. 
Table 2: Mapping between project investment growth opportunities and financial (stock) options

\begin{tabular}{l|l|l}
\hline \multicolumn{1}{c|}{ Investment Opportunity } & Variable & \multicolumn{1}{c}{$\begin{array}{c}\text { Stock Options } \\
\text { Equivalent }\end{array}$} \\
\hline $\begin{array}{l}\text { Present value of the cash flows obtained from the project } \\
\text { expansion (growth) option }\end{array}$ & $\mathrm{S}$ & Stock price \\
\hline Present value of the expenditure required for project expansion & $\mathrm{X}$ & Exercise (Strike) price \\
\hline Period that the project expansion option is available for & $\mathrm{t}$ & Time to expiration \\
\hline Uncertainty in the cash flow generated by the expansion option & $\sigma$ & Volatility of returns \\
\hline South African prevailing bond rate & $\mathrm{r}_{\mathrm{f}}$ & Risk-free rate \\
\hline
\end{tabular}

Source: Harmantzis \& Tanguturi (2007: 110)

Current / Market Price (S)

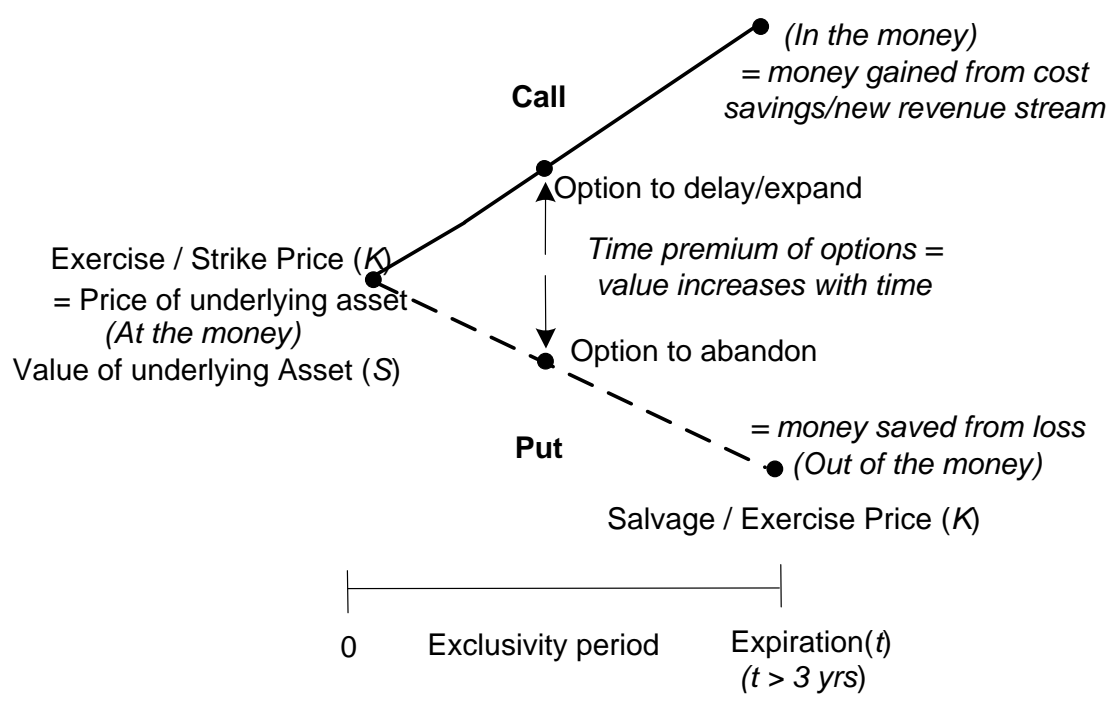

Figure 5: Illustration of an option pricing model

Source: Damodaran (2001: 391) [Adapted]

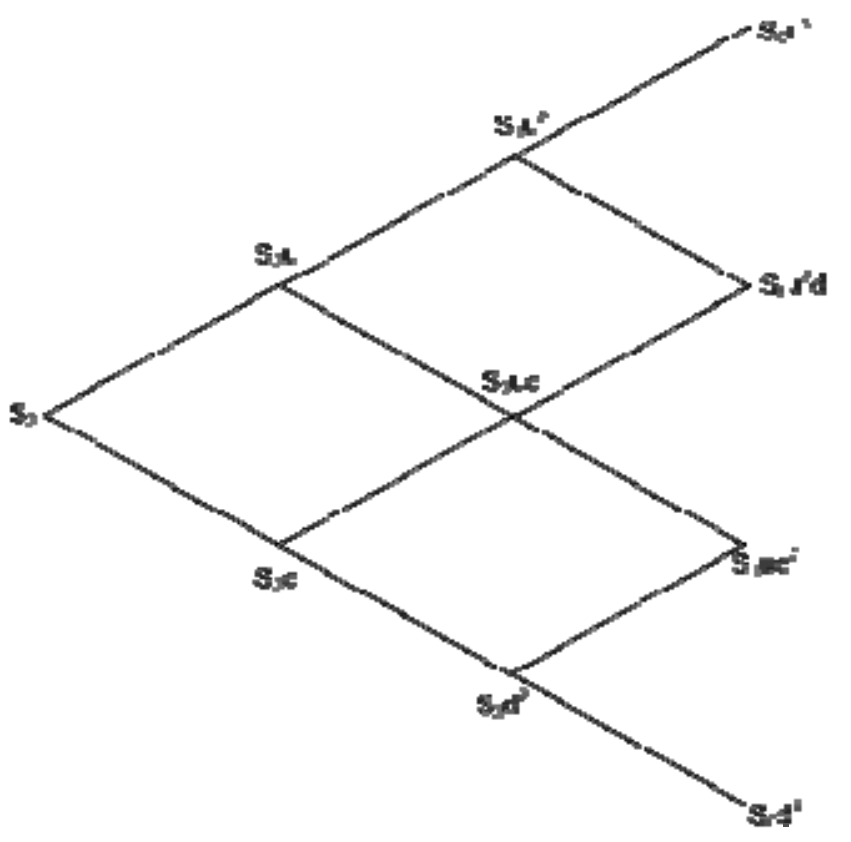

Figure 6: Binomial lattice representation for option valuation

Source: Mun (2006: 126)
The risk-neutral probability $(p)$ is calculated as follows in equation 16 (Mun, 2006, adapted):

$\mathrm{p}=\frac{\mathrm{e}^{(\mathrm{rf}-\mathrm{q})(\partial \mathrm{t})}-\mathrm{d}}{\mathrm{u}-\mathrm{d}}$

where:

$\mathrm{q}=$ the dividend.

In this application of real options analysis, it is assumed that no dividends are payable, therefore equation 16 is re-written as follows (Trigeorgis, 1996 cited in Svavarsson, 2004):

$p=\frac{e^{(\mathrm{rf})(\partial \mathrm{t})}-d}{u-d}$

The risk-neutral probability is a mathematical factor used in the lattice calculation, but has no particular meaning itself (Mun, 2006). As illustrated in Figure 6 above, the binomial lattice calculation process starts with the present value of the underlying investment at time zero $\left(\mathrm{S}_{0}\right)$. This value is then multiplied by up $(u)$ and down $(d)$ factors to create the binomial lattice. 
The binomial lattice method is used to estimate the value of a single-stage option in this study, and its results are compared to the results of the Black-Scholes method. The binomial lattice is well-suited for valuing compound (multistage) options such as a multi-stage options to expand; which could be created through multiple re-use of components in the SOA architecture (as illustrated in Figure 6 above). This is supported by Svavarsson (2004) who developed a binomial lattice model using a risk neutral probability approach for valuing real options in strategic IT platform investments. The model was used for the evaluation of strategic flexibility in the investment and, quantifying and managing the associated risks. The NGM architecture in this study is a type of next generation IT middleware implementation.

According to Mun (2006), a binomial lattice is a type of discrete simulation of uncertainties. Closed-form solutions are a stochastic process, represented by a continuous simulation of uncertainties, where a probability distribution can be constructed at each time period. This continuous simulation can be generated using the Geometric Brownian Motion with a fixed volatility as shown in equation 18 below.

$$
\frac{\partial \mathrm{S}}{\mathrm{S}}=\mu(\partial \mathrm{t})+\sigma \varepsilon \sqrt{\partial \mathrm{t}}
$$

where:

$$
\begin{aligned}
& \mu(\partial \mathrm{t}) \text { represents the deterministic part, and } \\
& \sigma \varepsilon \sqrt{\partial \mathrm{t}} \text { represents the stochastic part. }
\end{aligned}
$$

Solving a Brownian Motion in a discrete sense yields the binomial equations. Solving it in a continuous sense yields a closed-form equation such as the Black-Scholes.

According to Mun (2006), the second step is to solve the option valuation lattice. The option valuation lattice is calculated through a process called backward induction, moving from right (the terminal nodes) to left, and ending with the option value. The terminal nodes in the option valuation lattice are calculated by subtracting the project implementation cost from the terminal values. The intermediary nodes are calculated using a backward induction analysis equation represented below,

$$
[(p) u p+(1-p)] e^{-r f(\partial t)}
$$

where:

$$
p=\frac{e^{r f(\partial t)-d}}{u-d}
$$

The up and down values are the preceding up and down values going from right to left. As the discrete simulation steps were made smaller the binomial lattice option pricing model converged to a Black-Scholes option pricing model, resulting in a virtually identical value of the iCalled SM project right.

\section{Research results}

Based on equation 2 (above), the weighted average cost of capital (WACC) for the incumbent operator is $13,28 \%$. Due to the perceived project risk and operational risk, the project-specific hurdle rate is expected to be greater than the firm-specific WACC. The project complexity, represented by the degree of spending on specialized labour is assumed to be a reasonable risk proxy for project risk. In estimating the project risk, specifically due to implementation delay, the proportion of spending on project management, installation and commissioning relative to the total project spending is calculated. This estimate of $5 \%$ is used as a guideline to determine the project risk exposure. Similarly, the proportional spending on training relative to the total project spending is calculated and used as a guideline to determine the operational risk exposure. In this study, this estimate is $3 \%$. This risk estimation is assumed to be an upper bound risk. The lower bound project and operational risk are estimated to be $4 \%$ and $2 \%$ respectively. Therefore, the project-specific hurdle rate is estimated to be $19,28 \%$ (that is the sum of WACC of $13,28 \%$, project risk premium of $4 \%$ and operational risk premium of $2 \%$ ). The lower bound risk estimates are used as a conservative estimate to compute WACC.

The resulting risk-adjusted project-specific hurdle rate of $19.28 \%$ is used as the discount rate for the project cash flow, as illustrated in appendix A.2. Straight line depreciation is used for the 5 year period 2007 to 2011. The resulting passive NPV of the Next Generation Messaging (NGM) project investment over a 5 year period is estimated to be negative R2 143 911. This is a reflection of the high capital nature of the project, which is common for an investment of this nature, namely services infrastructure investment.

\section{Black-Scholes model}

Results of the Black-Scholes model are displayed in Table 3 below. Referring to equation 9 above, the total project investment value (in this study, the NGM project) is the sum of passive NPV and value of the option ranked priority number 1 (that is, option to expand). The total project investment value is negative R685 166 (that is negative R2 143911 plus positive R1 458745.

\section{Binomial Lattice model}

Table 4 (below) presents results of the Binomial Lattive Option Valuation model. 
Table 3: Name-value pairs for the Black-Scholes option

\begin{tabular}{c|c}
\hline Variable & Value \\
\hline Stock price $(\mathrm{S})$ & $3,161,717$ \\
\hline Strike price $(\mathrm{K})$ & $2,800,716$ \\
\hline Time in years $(\mathrm{t})$ & 5 years \\
\hline Volatility $(\sigma)$ & $6 \%$ \\
\hline Risk-free rate $\left(\mathrm{r}_{\mathrm{f}}\right)$ & $9,95 \%$ \\
\hline Variance & 0,0036 \\
\hline Annualised dividend yield & $0,00 \%$ \\
\hline $\mathrm{D} 1$ & 4,678898719 \\
\hline $\mathrm{N}(\mathrm{d} 1)$ & 0,999998558 \\
\hline $\mathrm{D} 2$ & 4,54473464 \\
\hline $\mathrm{N}(\mathrm{d} 2)$ & 0,99999725 \\
\hline Value of right & $+\mathbf{R 1 ~ 4 5 8 ~ 7 4 5}$ \\
\hline
\end{tabular}

Table 4: Results of a binomial lattice option valuation method

\begin{tabular}{c|c}
\hline Variable & Value \\
\hline PV Asset value (So) & R3 161 717 \\
\hline Implementation cost & R2 800 716 \\
\hline Maturity (years) & $9,95 \%$ \\
\hline Risk-free rate & $0,00 \%$ \\
\hline Dividends & $6,00 \%$ \\
\hline Volatility & 100 \\
\hline Lattice steps & European \\
\hline Option type & 0,05 \\
\hline Stepping time (dt) & 1,0135 \\
\hline Up step size (up) & 0,9867 \\
\hline Down step size (down) & 0,6825 \\
\hline Risk-neutral probability & R1 458 744 \\
\hline Auditing Lattice results (10 & \\
steps) & $\mathbf{+ R 1 ~ 4 5 8 ~ 7 4 5}$ \\
\hline Super Lattice results &
\end{tabular}

The valuation lattice is calculated in two steps (Mun, 2006:149). The first step in the lattice is to solve the binomial asset lattice through equations 15 and 17 (above). The results of which are illustrated in appendix B.1. The first node in the lattice (point $\mathrm{A}$ ) or $\left(S_{0}\right)$ is equal to the PV of cost savings from the iCalled SM project expansion option, which totals $\mathrm{R} 3,161,717$. Therefore the up node $\left(\mathrm{S}_{0} \mathrm{u}\right.$ referred to as point $\mathrm{B}$ in appendix B.1) is equal to R3,204,400 (that is R3,161,717 multiply by 1.0135 ), and the down node $\left(\mathrm{S}_{0} \mathrm{~d}\right.$ referred to as point $\mathrm{C}$ in appendix B.1) is equal to $\mathrm{R} 3,119,581$ (that is $\mathrm{R} 3,161,717$ multiplied by $0.9867)$. The process is repeated as indicated in Figure 6 (above) to show the evolution of the stock price $\left(\mathrm{S}_{0}\right)$ due to volatility $(\sigma)$ until the terminal values are reached on the right-most side of the lattice. This implies that after a period of 5 years, the PV of cost savings from the iCalled SM project expansion option could be anywhere between $\mathrm{R} 3,615,678$ and $\mathrm{R} 2,764,753$. These are far right top and bottom values, respectively (in appendix B.1). If the volatility was zero, the lattice would collapse into a straight line, so the terminal value of the lattice would simply be equal to $\mathrm{S}_{0}$.

The second step in the lattice is to solve the option valuation lattice, the results of which are illustrated in appendix B.2.
The option valuation lattice is calculated through a process called backward induction, moving from right (the terminal nodes) to left, and ending with the option value equal to positive $\mathrm{R} 1,458,745$ (point $\mathrm{D}$ on the lattice) in this instance. The terminal nodes in the option valuation lattice are calculated by subtracting the project implementation cost from the terminal values. The intermediary nodes are calculated using a backward induction analysis (that is equation 19 above). The up and down values are the preceding up and down values going from right to left. As the discrete simulation steps were made smaller the binomial model option pricing model converged to a BlackScholes option pricing model, resulting in a virtually identical value of the iCalled SM project right.

\section{Discussion, summary and conclusions}

Renkema (2000), cited in Svavarsson (2004), found that IT infrastructure investments often fuel innovations, leading to a sequence of investment phases with associated strategic value. This results in a complex valuation exercise. This study demonstrates similar findings to Svavarsson (2004). For example, the efficiency of the new service architecture design not only results in operational benefits (cost savings), but often provides a set of real options. The next-generation messaging (NGM) system assessed in this study was characterised by five non-mutually exclusive options-toexpand, namely; capacity demand management, network element consolidation, IT architecture consolidation, network efficiency, and new revenue stream.

The passive NPV of the next-generation messaging (NGM) project is estimated at negative R2.1 million, within a 5 year period. This is based on the static discounted cash flow analysis, where the costs and benefits (that is, revenues and cost savings) are estimated deterministically using basic time series forecasting. The risk-adjusted project cash flow discount rate used in the analysis is $19.28 \%$, compared to the firm's WACC of $13.28 \%$. The project-specific discount rate is based on the risk-free rate, project risk and operational risk.

The total investment value of the NGM project (also known as the active NPV) was estimated to be negative R685000, having factored in the embedded real option value (optionto-expand) of the iCalled SM option, which was ranked as priority number 1 in this study. A Black-Scholes model was used to estimate the option value, using a volatility (risk) value of $6 \%$. To validate the Black-Scholes model applied in the real option analysis, the results are compared with the binomial lattice approach's results using 100 lattice steps in estimating the option value. The option value is the same for both approaches. These results are similar to Damodaran's (2002) finding that when the binomial lattice model steps are made sufficiently small, the binomial option pricing model converges to a Black Scholes option pricing model. Mun's (2006) research results, where 100 to 1000 time-steps showed sufficiently good valuation approximation, support findings of this study. These results suggest that closed-form models such as Black-Scholes, traditionally used for valuing 
financial options can be used in the valuation of embedded options in next-generation service delivery technology architectures in the cellular telecommunications industry. This is despite their limited modelling flexibility as suggested by Mun (2006).

The in-the-money option-to-expand the NGM project (specifically, the iCalled SM expansion option) added a premium on the base value of the project. The option-todefer the NGM project, albeit an in-the-money benefit, indicated that it would not be of sufficient value to compensate for the expense of maintaining the existing legacy voicemail system. The base project (a nextgeneration messaging (NGM) project) is primarily an infrastructure project made up of hardware installation, software configuration and application customization (where necessary). It is essential that the costs and benefits are estimated deterministically for this approach to be feasible. As illustrated in Figure 1 (above), this is made possible by considering cash flows over a historical period and a forecast period which falls within the forecast budget horizon. The risky nature of the NGM project in a cellular operator environment requires the application of a projectspecific hurdle rate, which takes into account the project risk and operational risk in discounting the project cash flows. In this study, the project hurdle rate was estimated at $19.28 \%$, compared to the firm's WACC of $13.28 \%$, which supports the claim made by Ross et al. (2003) that WACC should only be applied to projects that share a similar profile to the firm risk, or risky projects are likely to be incorrectly accepted. For the non-probabilistic static cash flow method to yield reliable results however, despite the high discount rate, the volatility $(\sigma)$ in value-to-cost estimation is required to be relatively low.

In the case where the technology infrastructure has embedded options, such as the option to expand or option to defer, the result is a premium which is added to the passive NPV that was estimated through DCF analysis. Based on the findings of the iCalled SM option to expand project right, the resulting active NPV was substantially greater than the passive NPV, and would most likely positively influence the investment decision. The iCalled SM option-to-expand in this study resulted in a $68 \%$ premium being added to the base value of the NGM project. The NGM technology platform assessed in this study is recently introduced to the market, with no reference installations in the South African context, and hence no historical reference to volatility (risk). It is expected that the iCalled SM option to expand considered in this study will only be exercised in the long term time horizon (after year-5, dependant on successful completion of the base project), so there would be significant uncertainty $(\sigma \sqrt{ } \mathrm{t})$ in the value-to-cost estimation between year-5 and year-10. If the service provider took the decision to exercise the option early, the value of the iCalled SM project right would have to be re-evaluated.

The purpose of this study was to examine the application of non-probabilistic and probabilistic techniques such as static cash flow and real options in valuing technology investments in the cellular telecommunications industry.
This study has established that in the short to medium term time horizon (such as less than or equal to 5 years), static discounted cash flow (DCF) analysis can be applied successfully to a base project in next-generation technology investments in the cellular telecommunications industry. In addition to this, this study demonstrated that real option valuation techniques are suitable to value projects with strategic options. This is what Alleman (2002) referred to as flexibility provided to management.

However, this study is limited to the valuation of a base project in implementing a next-generation telecommunications service delivery architecture and some simple options associated with the project, such as the option-to-expand and the option-to-defer the investment. Further research is required to analyse the effect of compound options on the project value, and ultimately, to determine which combination of options would yield the maximum return for the shareholders.

\section{References}

Alleman, J. 2002. 'A new view of telecommunications economics', Telecommunications Policy, 26:87-92.

Anderson, T.J. 2000. 'Real options analysis in strategic decision making: An applied approach in a dual options framework', Applied Management Studies, 9(2):235-255.

Arboleda, C.A. \& Abraham, D.M. 2006. 'Evaluation of flexibility in capital investments of infrastructure systems', Engineering, Construction and Architectural Management, 13(3):254-274.

Athwal, B., Harmantzis, F. \& Tanguturi, V. P. 2005. 'Replacing centric voice services with hosted VoIP services - A real options approach.' In Proceedings of the 16th International Telecommunications Society (ITS) European Regional Conference, Porto, Portugal, September.

Benninga, S. \& Tolkowsky, E. 2002. 'Real options - An introduction and an application to R\&D valuation', The Engineering Economist, 47(2):151-168.

Bowman, E. \& Moskowitz, G. 2001. 'Real options analysis and strategic decision making', Organization Science, 12(6):772-777.

Carlsson, C. \& Fuller, R. 2002. 'A fuzzy approach to real option valuation', Fuzzy Sets and Systems, 13(9):297-312.

Creswell, J.W. 2003. Research design - qualitative, quantitative, and mixed methods approaches. $2^{\text {nd }}$ Edition. California: Sage Publications.

Dai, Q., Kauffman, R. J. \& March, S. T. 2000. 'Analyzing investments in object-oriented middleware: An options perspective.' In Proceedings of MIS Research Center Working Papers Carlson School of Management, Minneapolis, University of Minnesota, p.p.1-27. 
Dai, Q., Kauffman, R. J. \& March, S. T. 2007. 'Valuing information technology infrastructures: A growth options approach', Information Technology \& Management, 8(1):117.

Damodaran, A. 2001. The dark side of valuation. New Jersey: Prentice Hall.

Damodaran, A. 2002. Investment valuation - tools and techniques for determining the value of any asset. $2^{\text {nd }}$ Edition. New York: Wiley Finance.

Dixit, A. K. \& Pindyck, R. S. 1995. 'The options approach to capital investments', Harvard Business Review, 73:105115.

Ekstrom, M. \& Bjornsson, H. 2003. Evaluating IT investments in construction - accounting for strategic flexibility. CIFE Technical Report, No.136, Centre for Integrated Facility Engineering (CIFE) - Stanford University: California.

Hallman, G. \& McClain, C. 1999. 'Real options applications for telecommunications deregulation.' In Alleman, J. \& Noam, E. (eds.) The new investment theory of real options and its implication for telecommunications economics. Boston: Kluwer Academic Publishers, p.p.35-47.

Harmantzis, F.C. \& Tanguturi, V. P. 2005. 'Real options analysis for GPRS network with Wi-Fi integration.' In Proceedings of the 31st Annual Conference of the Northeast Business \& Economics Association, New York.

Harmantzis, F.C. \& Tanguturi, V.P. 2007. 'Investment decisions in the wireless industry applying real options', Telecommunications Policy, 31(2):107-123.
Pollet, T., Maas, G., Marien, J. \& Wambecq, A. 2006. 'Telecom services delivery in a SOA'. In Proceedings of the 20th International Conference on Advanced Information Networking and Applications (AINA'06), Volume 2, Vienna University of Technology, Vienna, Austria, IEEE Computer Society, p.p.529-533.

Ross, S., Westerfield, R.W. \& Jordan, B.D. 2003. Fundamentals of corporate finance, $6^{\text {th }}$ edition of the annotated instructror's edition. Berkshire: McGraw-Hill Education.

Sheppard, G.R. 2003. 'The raiseboring industry: Real option valuation as a decision making tool'. Unpublished MBA Thesis, University of the Witwatersrand, Johannesburg.

Sur, A., Skidmore, D. \& Chakravarty, S. 2006. 'Web services based SOA for next generation telecom networks'. In Proceedings of the Sixth IEEE International Conference on Services Computing (SCC'06), Chicago, USA, IEEE Computer Society, p.p.520-520.

Svavarsson, D. 2004. 'Evaluation of strategic IT platform investments'. In Proceedings of the 10th Americas Conference on Information Systems (AMCIS'04), New York, August 2004, New York Association for Information Systems.

Tiwana, A., Keil, M. \& Fichman, R.G. 2006. 'Information systems project continuation in escalation situations: A real options model', Decision Sciences, 37(3): 357-391.

Tiwana, A., Wang, J., Keil, M. \& Ahluwalia, P. 2007. 'The bounded rationality bias in managerial valuation of real options: Theory and evidence from IT projects', Decision Sciences, 38(1):157-181.

Hemscott. 2008. Cell C's senior secured notes put on negativeTrigeorgis, L. 1999. 'Real options: A primer'. In Alleman, watch - S\&P. [online] URL:

J. \& Noam, E. (eds.) The new investment theory of real http://www.hemscott.com/news/static/tfn/item.do?newsId=64888 options and its implication for telecommunications 367199236. Accessed $21^{\text {st }}$ June 2008. economics. Boston: Kluwer Academic Publishers, p.p.1-33.

Iatropoulos, A.D., Economides, A.A. \& Angelou, G.N. 2004. 'Broadband investments analysis using real options methodology', Communications \& Strategies, 55:45-76.

Jamison, M.A. 1999. 'Does practice follow principle? Applying real options principles to proxy costs in U.S. telecommunications'. In Alleman, J. \& Noam, E. (eds.). The new investment theory of real options and its implication for telecommunications economics.ist Edition. Boston: Kluwer Academic Publishers, p.p.35-47.

Mun, J. 2006. Real options analysis - tools and techniques for valuing strategic investments and decisions. $2^{\text {nd }}$ Edition. New Jersey: Wiley Finance.

Panayi, S. \& Trigeorgis, L. 1998. 'Multi-stage real options: The cases of information technology infrastructure and international bank expansion', Quarterly Review of Economics \& Finance, 38(4):675-692.
Yu, H., Lee, Z. \& Chang, S. 2005. 'Using a fuzzy multicriteria decision making approach to evaluate alternative licensing mechanisms', Information \& Management, 42: 517-531. 
Appendix A.1 Proposed DCF (NPV) analysis tool indicating project cashflow structure

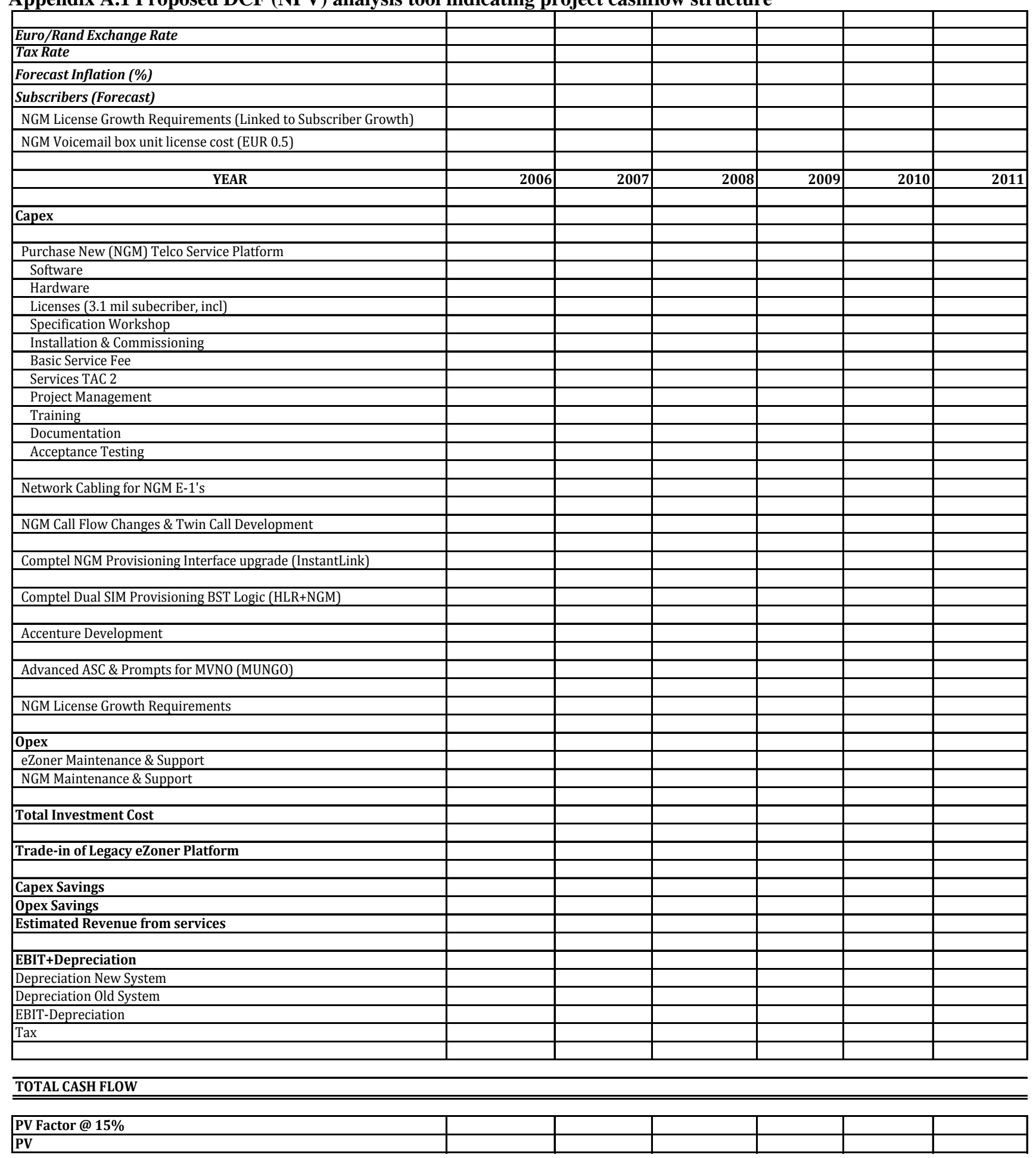


Appendix A.2: DCF (NPV) analysis of the Next Generation Messaging (NGM) project

Telecomms Next generation Messaging (NGM) Project

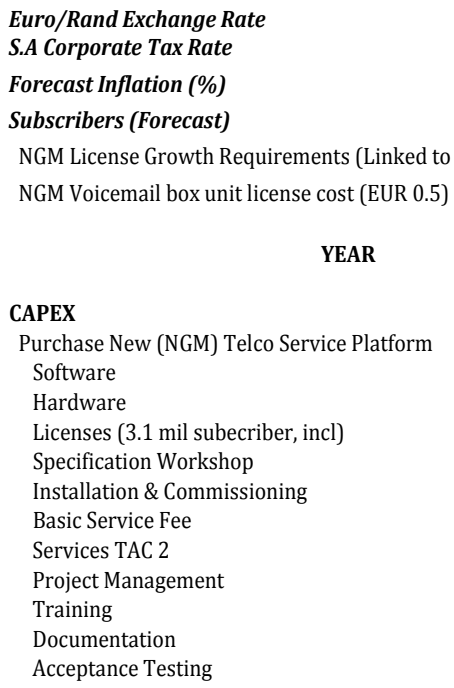

YEAR

\section{CAPEX}

Purchase New (NGM) Telco Service Platform

Software

Hardware

Licenses (3.1 mil subecriber, incl)

Specification Workshop

Installation \& Commissioning

Basic Service Fee

Services TAC 2

Project Management

Training

Documentation

Acceptance Testing

Network Cabling for NGM E-1's

NGM Call Flow Changes \& Twin Call Development

Comptel NGM Provisioning Interface upgrade (InstantLink)

Comptel Dual SIM Provisioning BST Logic (HLR+NGM)

Accenture Development

Advanced ASC \& Prompts for MVNO (MUNGO)

NGM License Growth Requirements (excluded from DCF -> Option to Expand)

\section{OPEX}

eZoner Maintenance \& Support

NGM Maintenance \& Support

Total Investment Cost

Trade-in of Legacy eZoner Platform

Capex Savings

Opex Savings

Estimated Revenue from services

EBIT+Depreciation
Depreciation New Systen

Depreciation New System
Depreciation Old System

EBIT-Depreciation

Tax

\section{TOTAL CASH FLOW}

PV Factor @ 19.28\%

PV

NPV @19.28\%

\section{Project Cash Flow Structure}

$\begin{array}{rrrrrr}28 \% & 9.92 & 12.44 & 12.44 & 12.44 & 12.44 \\ 4.6 & 7.1 & 10.2 & & & \\ 4,188,880 & 4,835,712 & 6,728,266 & 7,831,581 & 8,608,270 & 9,512,551 \\ & & 501,891 & 590,645 & 415,790 & 484,095 \\ & 4.96 & 6.22 & 6.22 & 6.22 & 6.22 \\ \mathbf{2 0 0 6} & \mathbf{2 0 0 7} & \mathbf{2 0 0 8} & \mathbf{2 0 0 9} & \mathbf{2 0 1 0} & \mathbf{2 0 1 1}\end{array}$
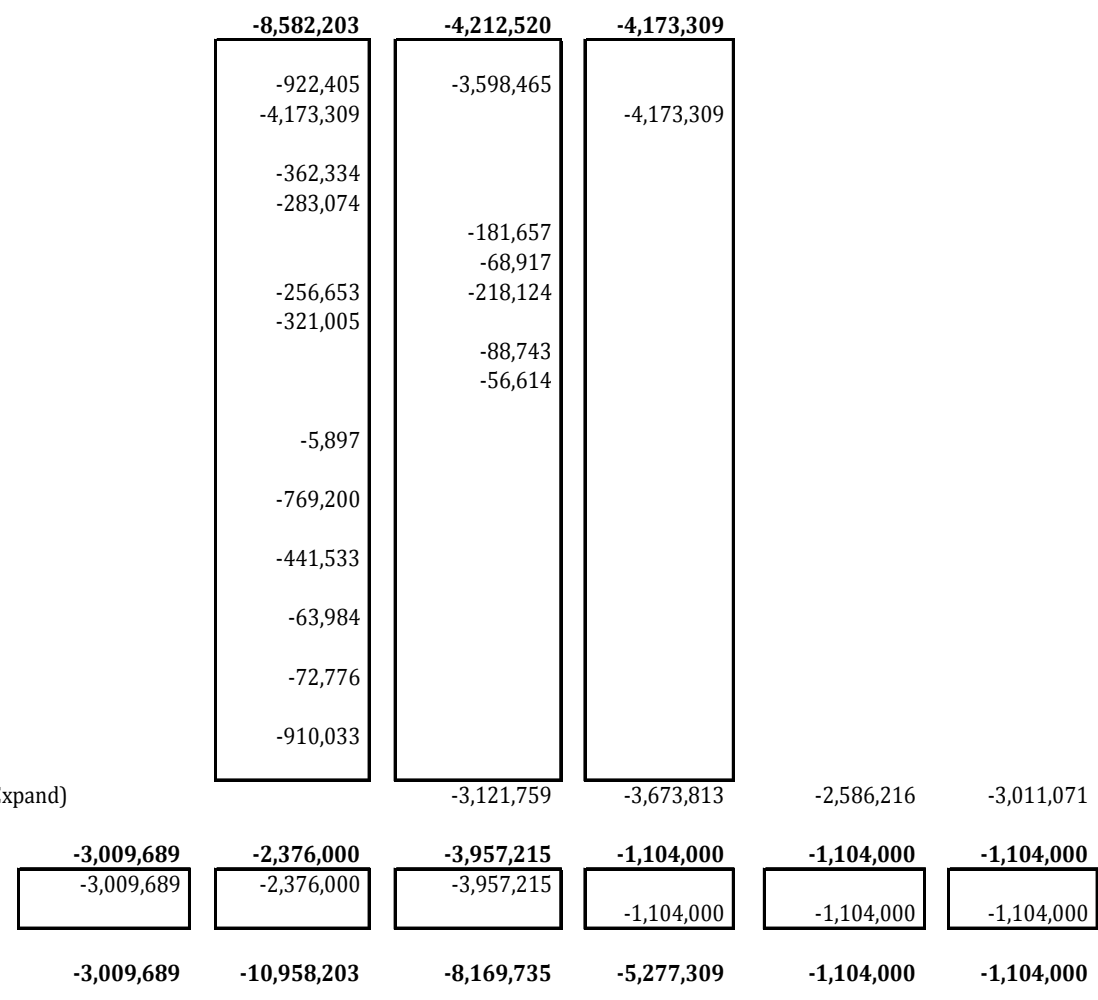

$2,290,871$

\begin{tabular}{|c|c|c|c|c|c|}
\hline $1,442,171$ & $1,664,866$ & $2,316,445$ & $\begin{array}{l}2,010,301 \\
2,696,300\end{array}$ & $\begin{array}{l}2,010,301 \\
2,963,703\end{array}$ & $\begin{array}{l}2,010,301 \\
3,275,034\end{array}$ \\
\hline \multirow[t]{7}{*}{$-1,567,518$} & $-9,293,337$ & $-3,562,419$ & $-570,707$ & $3,870,005$ & $4,181,335$ \\
\hline & $-3,393,606$ & $-3,393,606$ & $-3,393,606$ & $-3,393,606$ & $-3,393,606$ \\
\hline & $-12,686,943$ & $-6,956,025$ & $-3,964,314$ & 476,398 & 787,729 \\
\hline & $3,552,344$ & $1,947,687$ & $1,110,008$ & $-133,392$ & $-220,564$ \\
\hline & $-5,740,993$ & $-1,614,732$ & 539,301 & $3,736,613$ & $3,960,771$ \\
\hline & 1 & 1 & 1 & 0 & 0 \\
\hline & $-4,813,039$ & $-1,134,920$ & 317,781 & $1,845,898$ & $1,640,369$ \\
\hline
\end{tabular}

$-2,143,911$ 
Appendix B.1 Binomial Lattice illustration of the Project Expansion Option (NGM iCalled SM Project Option)

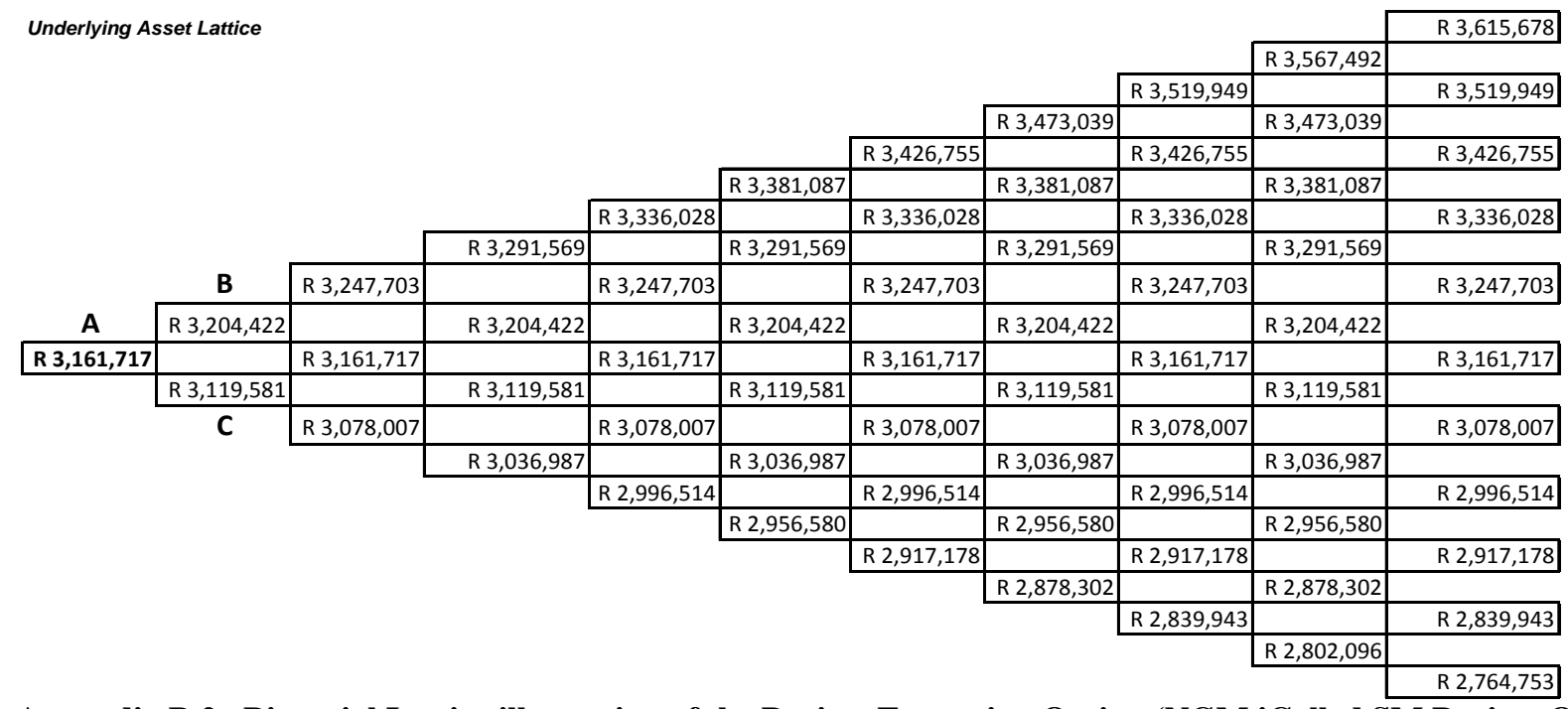

Appendix B.2 Binomial Lattice illustration of the Project Expansion Option (NGM iCalled SM Project Option)

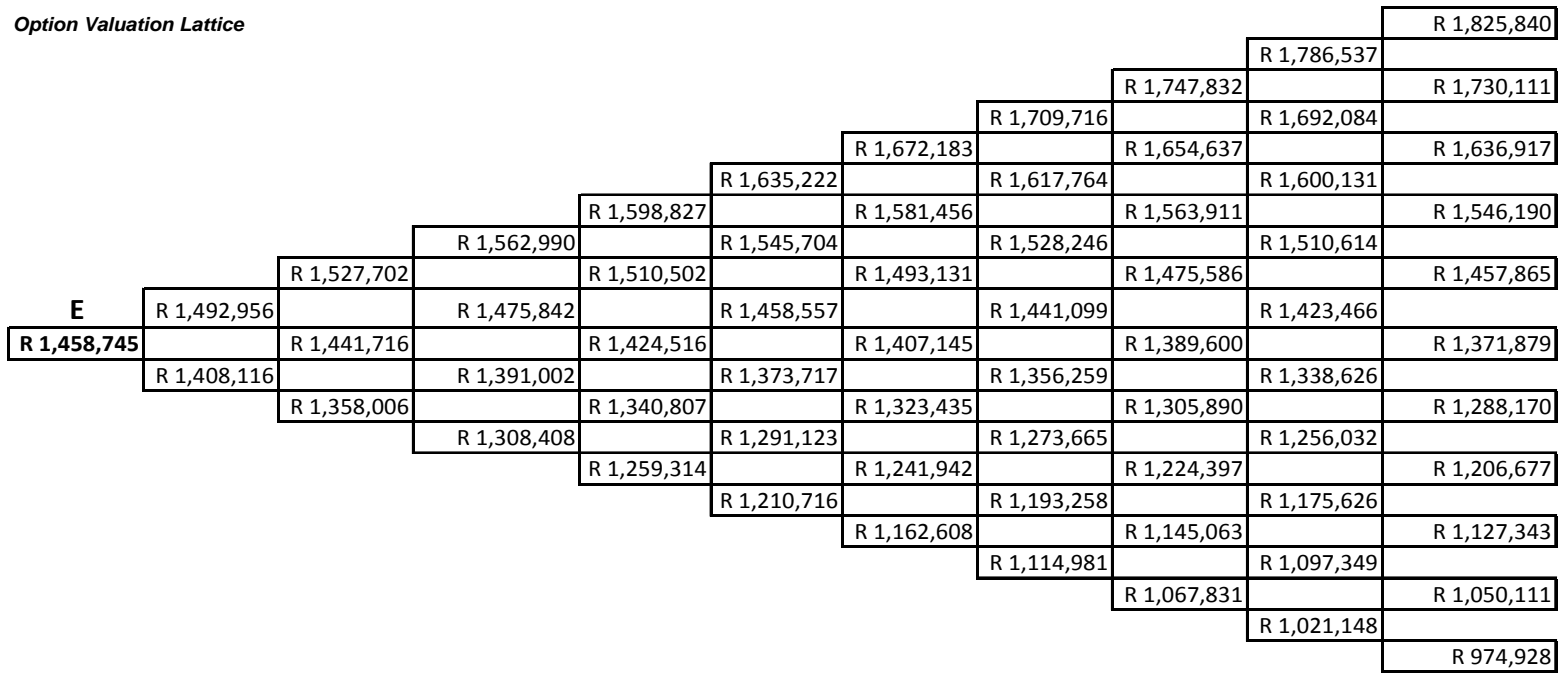


